\title{
A GEOGRAFIA E O ESTUDO DO ESPAÇO E DO TEMPO: A CONTRIBUIÇÃO DE OUTRAS CIÊNCIAS (UMA NOTA CRÍTICA)
}

\section{Geography and Study of Space and Time: Science other Contributions (A Note Critical)}

\author{
Marquessuel Dantas de Souza \\ Graduado em Geografia pela Faculdade de São Paulo \\ marquessuelgf@hotmail.com
}

Artigo recebido em 20/05/2015 e aceito para publicação em 11/12/2015

DOI: $10.12957 /$ tamoios.2015.16535

Resumo O texto aqui apresentado se propõe a chamar atenção da Geografia no que se refere ao estudo do espaço e do tempo no âmbito científico, embora a complexidade desta análise se mostre real, o entendimento de tal estudo não se torna impossível. Através da interdisciplinaridade ressalta-se a complementação no desenvolvimento da ciência. De todo modo, a Geografia necessita da Filosofia, da História, da Psicologia, da Economia, bem como da Física, Matemática, da Sociologia, entre outros campos do saber humano. Isto, para uma melhor compreensão da realidade que nos envolve. Uma metodologia que efetue uma prática equivalente torna-se necessária.

Palavras-chave: Geografia; Espaço; Tempo; Ciências; Crítica interdisciplinar.

Abstract The text presented here aims to draw attention Geography in relation to the study of space and time in the scientific, although the complexity of this analysis show real understanding this study did not impossible. Through interdisciplinary study highlights the complementary development of science. Anyway, Geography needs of Philosophy, History, Psychology, Economics and Physics, Mathematics, Sociology, among other fields of human knowledge. This, to a better understanding of the reality that surrounds us. A methodology to conduct a practice equivalent becomes necessary.

Keywords: Geography; Space; Time; Sciences; Interdisciplinary criticism. 


\section{INTRODUÇÃO}

Ao fazermos uma breve reflexão crítica acerca do objeto máximo dos e nos Estudos Geográficos (O Espaço), percebe-se que muito “conhecimento" elaborado continua oculto. Muitas referências encontram-se longe dos olhos dos estudantes de geografia e permanecem desconhecidas por parte dos mesmos. Muito material de excelente qualidade não são consultados para o desenvolvimento de uma pesquisa científica digna. - Neste contexto diz-se que nos cursos de Geografia, tanto na Graduação quanto na Pós-Graduação muito do saber humano em relação à discussão sobre o espaço e o tempo encontra-se distanciando ou não informado no sentido de não serem materiais de cunho geográfico. Em outros termos, para muitos geógrafos o estudo do espaço e do tempo em si pertence a outras áreas do conhecimento que não seja a Geografia. Quer dizer, quando da investigação espacial cita-se muitos, inúmeros autores da Geografia, por sua vez, esquecendo que primeiramente a ideia de Espaço parte da Filosofia, ou seja, ao discutir a noção de espaço os geógrafos devem saber que tal categoria/conceito não é originário da Ciência Geográfica. Portanto, os mesmos tem que buscarem outros meios para fundamentar seus argumentos, entre estes meios, está a Filosofia, principalmente. Bem como a Psicologia, a Sociologia, a História, a Física entre outros. Eis o porquê de evidenciar a Geografia e o estudo interdisciplinar do espaço e do tempo. Uma espécie de provocação geográfica.

Preocupação metodológica e epistemológica é o que se verifica nas linhas a seguir. Por uma epistemologia na geografia ou por um saber geográfico relevante, intentamos contribuir para a difusão da análise do tempo-espaço e do espaço-tempo relativos em suas constituições. Para tanto, há que utilizar-se de outros campos do saber para fundamentar os argumentos. - O presente texto, como uma nota crítica, direcionase para a compreensão do estudo referente ao espaço e ao tempo, conquanto, além da abordagem geográfica. Contudo, faz-se uma breve reflexão a tal respeito.

A proposta não quer ser um manual de consulta no que concerne ao espaço e ao tempo. Mas uma colaboração bibliográfica outra para com a ciência geográfica, em especial a geografia humana. Assim sendo, pode-se dizer que as crises que a própria geografia já viveu e ainda convive é da falta de uma melhor compreensão do significado do espaço e do tempo. Isto é, o espaço que a Geografia estuda continua sendo um equívoco. Pois antes de conceituar o espaço geográfico, o estudante de geografia deve ter a preocupação de decifrar o que é o espaço, por exemplo; bem como o tempo. 


\section{GEOGRAFIA, ESPAÇO E TEMPO: AVALIAÇÃO PRELIMINAR}

Bem entendido, algumas obras são clássicas no estudo do espaço, com efeito, a Geografia as utiliza para sua argumentação segundo a tradição do pensamento geográfico. Entrementes, buscando compreender também a ideia de Tempo, Mundo e Natureza. - Para tanto, a Física de Aristóteles, a Crítica da Razão Pura e os Princípios Metafísicos da Ciência da Natureza de Kant, especificamente, são as referências básicas. Contudo, convém dizer que a obra Principia de Newton, a Teoria da Relatividade de Einstein (embora lembrando que a ideia de relatividade já havia sido evocada por Leibniz em 1715 quando de sua correspondência com Clark), os Princípios da Filosofia de Descartes, tornam-se outras referências fundamentais. Não obstante, estas citações são vistas como dos estudos da Física e/ou da Filosofia e não da Geografia. Salientamos que se a Geografia partir da própria Geografia, a mesma não se move. Com isso chama-se atenção dizendo que é necessário os geógrafos terem consigo um leque amplo de informações oriundas de outros campos do saber para que suas "pesquisas" de investigação não sejam ou não se tornem trabalhos caricaturados. Além das obras citadas anteriormente, há trabalhos importantes como os de Bergson (em especial Duração e Simultaneidade), os de Bachelard (principalmente A Poética do Espaço e A Intuição do Instante), a Filosofia da Natureza de Hegel e de Schelling, os Conceitos de Espaço de Max Jammer, Ser e Tempo de Heidegger, A Filosofia das Formas Simbólicas III de Cassirer, O que é Tempo e O Tempo na História de Whitrow, A Natureza e Fenomenologia da Percepção de Merleau-Ponty, as Confissões de Santo Agostinho, apenas para citar alguns.

Analisar pormenorizadamente o que significa o Espaço e o Tempo é algo rejeitado por alguns geógrafos. Isto é, para profissionais geógrafos mecânicos e imediatistas e tecnólogos (geração século XXI, porquanto tradicionalistas), detalhar ou buscar decifrar o que são o espaço e o tempo é trabalho de filósofo ou de físico. - Ora, isto é absurdo. Refutamos tal proposição. Diz-se então afirmativamente: os geógrafos usam a ideia de espaço, que veio de outro campo do saber e acreditam serem os proprietários de tal ideia. Fazem o que bem entendem sobre ambos os conceitos. - O Tempo e o Espaço como categorias ou conceitos são debatidos, estudados e ou investigados por várias ciências. Por conseguinte, os geógrafos falam do espaço e do tempo, assim acreditamos, sem saberem o que estão dizendo. Deste modo, por que não procurar aprofundar o que são o tempo e o espaço? As preocupações mais recentes nos estudos geográficos são 
sobre o território, o meio ambiente, a área, o lugar, a paisagem, a região entre outros. Por vezes, envolvendo-os no conjunto no quais chamam de o espaço geográfico. Bem entendido, o espaço é o todo cósmico que envolve todos os outros pontos citados anteriormente.

Neste contexto indaga-se ousadamente: o espaço geográfico é diferente do espaço em si (espaço do espaço; espaço pelo espaço)? - O espaço tratado pela geografia é o da superfície da terra, claro. Mas esse espaço está fora do todo cósmico? - Físicos, filósofos e geógrafos vivem em espaços dessemelhantes? Certamente o espaço analisado pela Astronomia "talvez" seja diferente, mas o espaço nos quais filósofos e físicos (usando a mecânica) debatem é o espaço em que a geografia se faz presente. Grosso modo, o espaço dos físicos e dos filósofos é o mesmo espaço dos geógrafos, no sentido de base terrestre que sustenta a vida existencial. Destarte, os movimentos das partículas estudados pela física dá-se no geográfico, a compreensão filosófica do espaço e do tempo não se distancia muito daquilo que é geográfico (geográfico entendido aqui como tudo aquilo que envolve a hidrosfera, a litosfera, a atmosfera e que se constitui em Biosfera).

Pensar sobre o tempo e o espaço não é o mesmo que estar no tempo e no espaço. Certamente, um conceito envolve o outro. Isto é fácil de compreender, mas a questão que se coloca é: o que é o espaço e o que é tempo para os geógrafos? Serão os geógrafos cientistas dos lugares, das paisagens, dos meios, dos territórios e etc., e não do espaço? A Geografia para afirmar-se como ciência independente adapta ou reformula conceitos advindos de outros campos do saber, quase que desencontrada e esquecendo a originalidade dos termos. - Onde está a Geografia? Os geógrafos estão adormecidos em plena vigilância? Ainda mais: a geografia cita frequentemente em seus discursos "espaços" - no plural -, algo como um conhecimento querendo afirmar-se desesperadamente. Pois como sabemos a Filosofia não é considerada ciência. Por sua vez, permanece convicta de seus propósitos e mantém seu método integral. Ao passo que a Geografia ao longo dos séculos (XIX-XX) mudou de perspectiva (metodologia) algumas vezes. Com efeito, por que a Geografia cria vários espaços classificando-os? É falta de conhecimento psicossensorial daqueles que a promovem, ou realmente a Geografia é um aparelho/instrumento ideológico para manipulação do real? Em que tipo de sociedade vivemos? O que é ciência, efetivamente?

Ademais, pergunta-se: o espaço e o tempo em realidade existem como instâncias existências ou são criações humanas? São dimensões exteriores ou interiores? Espaço e 
tempo constituem uma ou duas instâncias? São instâncias diferentes ou não? Apesar de existirem respostas variadas e demasiadamente complexas e outras, no entanto simples, há estudos confrontando ambas as proposições. Assim sendo, será que os geógrafos sabem disso? - Nossa intenção não é responder a estas inusitadas e tão comuns indagações, mas instigar o raciocínio geográfico a promover outras mais. Com efeito, buscar estudar outros campos do saber para uma possível elaboração geográfica dos termos (entenda-se aqui elaboração geográfica como conhecimento interdisciplinar). Haja vista ser a Geografia uma entre muitas ciências e um entre inúmeros meios de conhecer ou decifrar (traduzir) o mundo, e não o único (a).

- Poucos estão habituados com um discurso semelhante a este. Por isso, talvez, o mesmo seja um devaneio ou uma utopia para o leitor. Mas não é esse o propósito. O presente texto delineia-se como uma inquietação, um olhar outro sobre os estudos geográficos, todavia, audacioso. - Crê-se que o grande problema de a Geografia estudar o espaço é que o delimitam a visão. Ou seja, coloca-se que o espaço é o material, portanto o que tem forma (pensamento aristotélico-kantiano). Neste sentido, fica mais fácil manejá-lo, teórico e empiricamente (em especial quando se refere ao trabalho de campo e a ideologia); o que provoca equívoco. O mesmo ocorre quando delimitam o tempo entre estações sazonais e a climatologia. - O tempo não é isso. O tempo é algo "qualitativo", assim como o espaço. Qualitativo no sentido de promover a realização existencial. Assim pode-se dizer que tempo e espaço não se movem (apesar de suas relatividades). Espaço e tempo não envelhecem. Espaço e tempo não são e não possuem dimensões métricas. Em essência, usando linguagem simples, afirma-se que espaço e tempo não se veem não se ouvem e não se tocam. - Partindo desse pressuposto, acreditamos que a Geografia está buscando espacializar o que não é possível. Para tanto, isto requer e exige esforço para um trabalho de investigação aprofundando os argumentos. Algo inviável neste simples e curto escrito. Apenas intenta-se uma rápida reflexão a fim de instigar outros tantos debates nesta direção.

A grande façanha e o triunfo em relação ao espaço-tempo é mostrar que as ideias aristotélicas e kantianas ainda permeiam todo o discurso geográfico e os próprios geógrafos não percebem nitidamente este acontecimento. Quer dizer, apesar de muitos geógrafos negarem o discurso aristotélico-kantiano na geografia, não podemos fugir desta verdadeira relação. - Um adendo: os grandes geógrafos clássicos tais como Humboldt, Ritter, Ratzel, La Blache, Elisée Reclus e outros mais, são poucos estudados na contemporaneidade. Algo que empobrece em muito a Geografia. Estes autores 
precisam ser mais explorados rigorosamente no século XXI, assim como outros (evoquemos uma possível psicologia do tempo e do espaço). Por exemplo, Ratzel na Obra Espaço e Tempo na Geografia e Geologia (1907), nos diz, parafraseando-o: espaço vazio é impossível, assim como é impossível o tempo infinito (concepção aristotélico-kantiana).

- Além das obras citadas ao longo do texto, fora elaborado de forma breve, uma lista de obras (de autores) que podem auxiliar os geógrafos na questão espacial e temporal. Estas obras apresentam definições qualitativas sobre o que são o espaço e o tempo. São trabalhos, grosso modo, de envergadura filosófica e física (e psicológica) e que podem servir amplamente para o desenvolvimento da compreensão de ambos os conceitos na Geografia. Alguns dos textos são conhecidos no Brasil como os de Bachelard (já citados), Bettanini (Espaço e ciências humanas), Milton Santos (A natureza do espaço), Armando Corrêa da Silva (O espaço fora do lugar e De quem é o pedalo?) e de Tuan (Espaço e lugar), Lacey (A Linguagem do Espaço e do Tempo), Lefebvre (Espaço e política). Já outros são trabalhos inéditos para muitos estudantes geógrafos, textos estes desconhecidos pela comunidade geográfica brasileira. Alguns dos mesmos são escritos raros. - Ressalta-se que muitos outros textos da mesma importância existem, contudo, não foram citados. Apenas alguns. Do mesmo modo salienta-se que muito sobre espaço e tempo estão registrados em artigos científicos e em capítulos de coletâneas. Bem como em monografias (dissertações de mestrado e teses de doutorado, principalmente). Assim como em muitos romances, poemas, contos e crônicas (em vários países: várias línguas). Em sentido igual chama-se atenção para que não nos limitemos aos estudos efetuados apenas pela cultura ocidental. No oriente há muita coisa riquíssima em se tratando de reflexão, em geral. - Alguns textos do budismo e do hinduísmo, por exemplo, possuem uma excelente contribuição para com o entendimento do que é o tempo e o que é o espaço. Claro, estudando-os cientificamente.

Segue-se abaixo a lista de algumas obras e de alguns autores que tratam ou discutem o que são o espaço e o tempo, e podem ser estudados pela geografia a fim de somar ou contribuir para o desenvolvimento do entendimento sobre os mesmos:

Aristóteles - Metafísica. Victorino de Souza Alves - Conhecimento Metafísico do Espaço e Tempo. Almir de Andrade - As Duas Faces do Tempo. Antologias Universales - El Tiempo y el Espacio. Joaquin Vallejo Arbelaez - El Misterio del Tiempo. R. Argentière - Espaço, Tempo e Matéria. I. F. Askin - O Problema do Tempo. Émile Borel - l'Espace et le Temps. M. Cittanova - Analyse Psychologique des notions 
d'espace de temps et de relativité. Stephen Hawking e Roger Penrose - A Natureza do Espaço e do Tempo. Shuichi Kato - Tempo e Espaço na cultura japonesa. Georges Lechalas - Étude sur l'Espace et le Temps. Lídio Machado Bandeira de Mello Metafísica do Espaço. Lídio Machado Bandeira de Mello - Metafísica do Tempo. Désiré Nys - La Notion de Temps. Désiré Nys - La Notion d'Espace. Désiré Nys - La Notion d'Espace au point de vue cosmologique et psycologique. Bernard Piettre Filosofia e Ciência do Tempo. Fernando Pinhão - A Teoria do Espaço. Jean Pucelle El Tiempo. Friedrich Ratzel - Raum und Zeit in Geographie und Geologie. Christopher Ray - Tempo, Espaço e Filosofia. Hans Reichenbach - De Copérnico a Einstein. Douglas Santos - A Reinvenção do Espaço. Emile Sevin - Le Temps Absolu et l'espace a quatre dimensions. Edmund Husserl - Fenomenología de la conciencia del tiempo inmanente. V. I. Sviderski - Espacio y Tiempo. Robert Wallis - Le Temps, quatrième dimension de l'esprit. Norbert Elias - sobre o Tempo. Géza Szamosi - Espaço e Tempo: as dimensões gêmeas. Orieste Gomes - Reflexões sobre Teoria e Crítica em Geografia. Jean Piaget - A Noção de tempo na criança. Jean Piaget e Bärbel Inhalder - A Representação do espaço na criança.

\section{CONSIDERAÇÕES}

Após direcionar uma breve crítica e evocar alguns escritos (autores) relacionados ao estudo do espaço e do tempo, é o momento para dizermos que o avanço ou a evolução significativa de qualquer conhecimento (qualquer ciência) é de fundamental importância confrontarmos as ideias, compara-las, aderi-las, refuta-las, entre outras coisas. - Confrontar ideias (opostas ou não), consideramos como a melhor metodologia a ser utilizada para se chegar há resultados satisfatórios. Assim, há de acrescentar o valor particular de cada ramo do saber como um todo complexo. Nisto, considera-se a interdisciplinaridade um caminho bastante aceitável para atingir àquilo pretendido.

Decerto, o texto apresentado pareceu-nos paradoxal por evocar algumas situações, porém, sem conceituações específicas; mas isto merece um aprofundamento mais rigoroso das ideias, como já referido. Com efeito, a intenção fora fazer alguns apontamentos pensando nos estudos futuros; uma nota no qual se restringiu em detalhar todas as obras citadas; algo que melhor pretendemos desenvolver no por vir, havendo possibilidade. 
Considera-se que o escrito é uma provocação para com a Geografia. Todavia, preliminar ou introdutória, por vezes, se diz interpretativa àquilo que diz respeito ao espaço e ao tempo como conceitos básicos no estudo da sociedade humana, em suma, da existência (os grifos no corpo do texto são nossos).

\section{REFERÊNCIAS}

AGOSTINHO, St $^{\circ}$. Confissões. (Tradução de J. Oliveira Santos e A. Ambrósio de Pina) São Paulo: Nova Cultural, 1999, 416p.

ALVES, Victorino de Souza. Conhecimento Metafísico do Espaço e Tempo. In: Revista Portuguesa de Filosofia. Braga, julho/setembro, tomo XV, fasc. 3, pp. 262307, 1959. 336p.

ANDRADE, Almir de. As Duas Faces do Tempo: ensaio crítico sobre os fundamentos da filosofia dialética. São Paulo: José Olympio/Editora da Universidade de São Paulo, 1971. 652p.

ANTOLOGIAS UNIVERSALES. El Tiempo y el Espacio. (Selección y prólogo de Antonio G. Birlan) Buenos Aires: Americalee, 1956. 191p.

ARBELAEZ, Joaquin Vallejo. El Misterio del Tiempo. [Bogotá]: Italgraf, [1976]. 369p.

ARISTÓTELES. Metafísica. $2^{\mathrm{a}}$ edição. (Tradução, textos adicionais e notas Edson Bini) São Paulo: Edipro, 2012. 368p. (Série Aristóteles. Clássicos Edipro)

Física. (Introducción, traducción y notas de Guillermo R. de Enchandía)

Madrid: Editorial Gredos S. A., 2002. 508p. (Biblioteca Clásica Gredos; 203)

ARGENTIÈRE, R. Espaço, Tempo e Matéria. São Paulo: Edições Pincar, 1958. 159p. (Coleção ciência e divulgação)

ASKIN, I. F. O Problema do Tempo: sua interpretação filosófica. (Tradução de Joel Silveira) Rio de Janeiro: Paz e Terra, 1969. 220p.

BACHELARD, Gaston. A Intuição do Instante. $2^{\mathrm{a}}$ edição. (Tradução Antonio de Padua Danesi) Campinas: Verus, 2010. 104p.

La Poética del Espacio. Primera edición em español. (Traducción de Ernestina de Champourcin) México-Buenos Aires: Fondo de Cultura Económica, 1965. 303p. (Breviarios; 183)

BERGSON, Henri. Duração e Simultaneidade: a propósito da teoria de Einstein. (Tradução Claudia Berliner) São Paulo: Martins Fontes, 2006. 250p. (Tópicos)

BETTANINI, Tonino. Espaço e Ciências Humanas. (Tradução de Liliana Laganá Fernandes; revisão técnica de Moacyr Marques) Rio de Janeiro: Paz e Terra, 1982. 157p. (Coleção Geografia e sociedade; v. 2) 
BOREL, Émile. l'Espace et le Temps. Paris: Presses Univesitaires de France, 1949. 192p.

CASSIRER, Ernst. A Filosofia das Formas Simbólicas. Terceira parte fenomenologia do conhecimento. (Tradução Eurides Avance de Souza) São Paulo: Martins Fontes - selo Martins, 2011. 826p. (Tópicos)

CITtanova, M. Analyse Psychologique des notions d'espace de temps et de relativité: essai de philosophie scientifique sur l'espace et le temps. Paris: Les Editions Adyar, 1932. 368p.

DESCARTES, René. Princípios da Filosofia. ( $1^{\mathrm{a}}$ ed. do original de 1644). $2^{\mathrm{a}}$ edição. (Tradução de Ana Cotrim e Heloisa da Graça Burati) São Paulo: Rideel, 2007. 288p. (Biblioteca Clássica)

EINSTEIN, Albert. A Teoria da Relatividade Especial e Geral. $3^{\text {a }}$ reimpressão. (Tradução do original alemão Carlos Almeida Pereira). Rio de Janeiro: Contraponto, 2001. 136p.

ELIAS, Norbert. Sobre o Tempo. (Editado por Michael Schröter; tradução Vera Ribeiro) Rio de Janeiro: Jorge Zahar, 1998. 166p.

GOMES, Orieste. Reflexões sobre Teoria e Crítica em Geografia. Goiânia: CEGRAF/UFG, 1991. 121p.

HAWKING, Stephen \& PENROSE, Roger. A Natureza do Espaço e do Tempo. (Tradução Alberto Luiz da Rocha Barros) Campinas: Papirus, 1997. 160p. (Coleção Papirus Ciência)

HEGEL, Georg Wilhelm Friedrich. Enciclopédia das Ciências Filosóficas em Compêndio (1830): A Filosofia da Natureza. Volume II. (Tradução Pe. José Nogueira Machado com a colaboração de Paulo Meneses) São Paulo: Edições Loyola, 1997. $557 \mathrm{p}$.

HEIDEGGER, Martin. Ser e Tempo. $5^{\text {a }}$ edição. (Tradução revisada e apresentação de Márica Sá Cavalcante Schuback; posfácio de Emmanuel Carneiro Leão). Petrópolis: Vozes/Bragança Paulista: Editora Universitária São Francisco, 2011. 598p. (Coleção Pensamento Humano)

HUSSERL, Edmund. Fenomenología de la conciencia del tiempo inmanente. El tiempo em Husserl y en Heidegger por Ivonne Pecard. (Traducción de Otto E. Langfelder) Buenos Aires: Editorial Nova, [1959]. 209p.

JAMMER, Max. Conceitos de Espaço: a história das teorias do tempo na física. (Tradução da terceira edição ampliada Vera Ribeiro; apresentação Albert Einstein) Rio de Janeiro: Contraponto/Ed. PUC-Rio, 2010. 324p.

KANT, Immanuel. Crítica da Razão Pura. (Tradução Lucimar A. Coghi Anselmi e Fúlvio Lubisco) São Paulo: Martin Claret, 2009. 540p. (Coleção a obra prima da cada autor; 3. Série Ouro)

Princípios Metafísicos da Ciência da Natureza. (Tradução Artur Mourão) Lisboa: Edições 70, 1990. 128p. (Textos filosóficos; 28) 
KATO, Shuichi. Tempo e Espaço na cultura japonesa. (Tradução Neide Nagae e Fernando Chamas) São Paulo: Estação Liberdade, 2012. 288p.

LACEY, Hugh M. A Linguagem do Espaço e do Tempo. (Tradução Marcos Barbosa de Oliveira) São Paulo: Perspectiva, 1972. 265p. (Debates; 59)

LECHALAS, Georges. Étude sur l'Espace et le Temps. Félix Alcan: Paris, 1896. 201p.

LEFEBVRE, Henri. Espaço e Política. (Tradução Margarida Maria de Andrade e Sérgio Martins) Belo Horizonte: Editora UFMG, 2008. 192p. (Humanitas Pocket)

MELLO, Lídio Machado Bandeira de. Metafísica do Espaço: o problema da quarta dimensão. Edição manuscrito pelo autor. Belo Horizonte, 1966. 277p.

260p.

Metafísica do Tempo. Edição manuscrito pelo autor. Belo Horizonte, 1960.

MERLEAU-PONTY, Maurice. A Natureza. Curso do Collége de France. $2^{\mathrm{a}}$ ed. (Texto estabelecido e anotado por Dominique Séglard; Tradução Álvaro Cabral) São Paulo: Martins Fontes, 2006a. 466p. (Tópicos)

Fenomenologia da Percepção. $3^{\mathrm{a}}$ ed. (Tradução Carlos Alberto Ribeiro de Moura) São Paulo: Martins Fontes, 2006b. 666p. (Tópicos)

NEWTON, Isaac. Principia: Princípios Matemáticos de Filosofia Natural - Livro I. (1 ${ }^{\mathrm{a}}$ ed. do original de 1686). $2^{a}$ ed. $2^{a}$ reimpressão. (Tradução de Trieste Ricci; Leonardo Gregory Brunet; Sônia Terezinha Gehring e Maria Helena Curcio Célia, com apêndice histórico e explicativo por Florian Cajori) São Paulo: Edusp, 2012a. 328p.

Principia: Princípios Matemáticos de Filosofia Natural - Livro III. ( $1^{\text {a }}$ ed. do original de 1686). $1^{\mathrm{a}}$ ed. $1^{\mathrm{a}}$ reimpressão. (Tradução de André Koch Torres Assis, com apêndice histórico e explicativo por Florian Cajori) São Paulo: Edusp, 2012b. 448p.

NYS, D. La Notion de Temps. Troisième édition, revue, remaniée, augmentée. Louvain: Institut de Phisolophie. Paris: Félix Alcan, 1925. 312p. (Cours de philosophie; volume VII - Tome III -)

La Notion d'Espace. Bruxelles: Les Éditions Robert Sand, 1922. 446p.

La Notion d'Espace au point de vue cosmologique et psycologique. Louvain: Institut supérieur de philosophie, 1901. 295p.

PIAGET, Jean. A Noção de Tempo na Criança. $2^{a}$ edição. (Tradução Rubens Fiúza) São Paulo: Record, 2002. 462p.

PIAGET, Jean e INHALDER, Bärbel. A Representação do Espaço na Criança. (Tradução de Bernardina Machado de Albrquerque) Porto Alegre: Artes Médicas, 1993. 510p.

PIETTRE, Bernard. Filosofia e Ciência do Tempo. (Tradução Maria Antonia Pires de C. Figeuiredo) Bauru: Edusc, 1997. 224p. 
PINHÃO, Fernando. A Teoria do Espaço: estudo sobre a origem e a finalidade da existência material ou subsídios para a futura história universal. Rio de Janeiro: Pongetti, 1960. 142p.

PUCELLE, Jean. El Tiempo. Buenos Aires: El Ateneo, 1976. 96p. (Biblioteca de filosofia)

RATZEL, Friedrich. Raum und Zeit in Geographie und Geologie. Naturphilosophisch Betrachtungen. (Heraugegeben von Paul Barth) Leipzig: Johann Ambrosius Barth, 1907. 186p. (Natur - und Kulturphilosophisch Bibliotek; Band IV).

RAY, Christopher. Tempo, Espaço e Filosofia. (Tradução Thelma Médice Nóbrega; revisão técnica Oswaldo Pessoa Junior) Campinas: Papirus, 1993. 315p. (Coleção Papirus Ciência)

REICHENBACH, Hans. De Copérnico a Einstein. (Traducción del inglês por León Mirlas) Buenos Aires: Editorial Poseidon, 1945. 180p.

SANTOS, Douglas. A Reinvenção do Espaço: diálogos em torno da construção do significado de uma categoria. São Paulo: Editora Unesp, 2002. 218p.

SANTOS, Milton. A Natureza do Espaço: técnica e tempo, razão e emoção. $4^{\mathrm{a}}$ edição, $6^{\text {a }}$ reimpressão. São Paulo: Edusp, 2011. (Coleção Milton Santos; 1)

SCHELLING, Friedrich Wilhelm Joseph von. Escritos sobre Filosofía de la Naturaleza. (Estudio preliminar, traducción e notas de Arturo Leyte) Madrid: Alianza Editorial, 1996. 280p. (Alianza Universidad)

SEVIN, Emile. Le Temps Absolu et l'espace a quatre dimensions (lagravitation - la masse - la lumière). (Préface de M. Maurice d'Ocagne) Paris: Dunod, 1934. 127p.

SILVA, Armando Corrêa da. O Espaço Fora do Lugar. Segunda edição. São Paulo: Hucitec, 1988. 128p.

De quem é o pedaço? Espaço e Cultura. São Paulo: Hucitec, 1986.168p.

SVIDERSKI, V. I. Espacio y Tiempo: ensayo filosófico. (Traducción directa del ruso) Montevideo: Ediciones América Nueva, 1960. 223p.

SZAMOSI, Géza. Espaço e Tempo: as dimensões gêmeas. (Tradução Jorge Enéas Forte e Carlos Alberto Medeiros) Rio de Janeiro: Jorge Zahar, 1988. 277p.

TUAN, Yi-Fu. Espaço e Lugar: a perspectiva da experiência. (Tradução de Lívia de Oliveira) Londrina: Eduel, 2013. 248p.

WALLIS, Robert. Le Temps, quatrième dimension de l'esprit: étude de la fonction temporelle de l'homme du point de vue physique, biologique et méta-physique. (Préface de O. Costa de Beauregard) Paris: Flammarion, 1966. 275p.

WHITROW, G. J. O Que é Tempo? uma visão clássica sobre a natureza do tempo. (Tradução Maria Ignez Duque Estrada) Rio de Janeiro: Jorge Zahar, 2005. 208p.

O Tempo na História: concepções do tempo da pré-história aos nossos dias. (Tradução Maria Luiza X. de A. Borges) Rio de Janeiro: Jorge Zahar, 1993. 243p. (Coleção Ciência e Cultura) 